UDC 614.7: 658.56

doi.org:10.31684/2541-8475.2019.1(13).3-6

\title{
EXPERIENCE OF THE ACCREDITED SCIENTIFIC LABORATORY FOR MEASURING PHYSICAL FACTORS OF THE ENVIRONMENT
}

\author{
Altai State Medical University, Barnaul
}

\section{B.A. Balandovich, N.Yu. Tulin, A.V. Kurochkina, A.O. Pasechenko}

\begin{abstract}
The article presents the first results of the work of the accredited scientific Laboratory of Labour Conditions Hygienic Monitoring of the Institute of Occupational Health and Industrial Ecology of ASMU on carrying out the measurements of environment physical factors. Particular attention is paid to the experience of introduction of original approaches in the study of physical and radiation factors of the environment, which allows adapting generally accepted methods to the conditions of the environment and obtaining reliable and objective results, as evidenced by interlaboratory comparative tests organized by an accredited provider.
\end{abstract}

Key words: accredited laboratory, physical factors, environment, measurement means, measurement procedures, interlaboratory comparative tests.

Since the entry of the Scientific Test Laboratory of the Institute of Occupational Health and Industrial Ecology of ASMU of the Ministry of Health of the Russian Federation into the Register of Accredited Persons of the National Accreditation System on 16.07.2018 to the present time, the priority areas of laboratory research were the assessment of the impact of electromagnetic radiation levels (EMR) from transmitting radio engineering objects (TREO), radiation control of scrap metal vehicles leaving the Altai Krai, industrial control of harmful physical factors in the workplaces of organizations in our region, as well as expert evaluation of land and buildings upon completion of construction, major maintenance and reconstruction. All these areas are provided with appropriate normative methods of research of physical factors of the environment and the production environment in the area of accreditation of the Laboratory of Labour Conditions Hygienic Monitoring. At the same time, the application of these methods in some cases requires non-standard approaches aimed at the greatest possible adaptation of the measurement means under use to the actual conditions of the environment.

\section{Materials and methods}

The research of physical factors in laboratory activity priority areas was carried out in cooperation with the accredited inspection body of the Institute of Occupational Health and Industrial Ecology according to the implemented laboratory test quality management system, which includes 5 main block processes: obtaining a motivated task for conducting laboratory tests, drawing up a research program, preparation of measurement means, direct conducting of laboratory tests, analysis and evaluation of the results obtained. During the stated period, 154 radio transmission facilities located in 52 populated areas of the Altai Krai and the Altai Republic have been surveyed, including the cities of Barnaul, Novoaltaysk, Biysk,
Rubtsovsk, Zarinsk, Aleysk, Yarovoye, GornoAltaysk, and 44 villages in 18 municipalities. A total of 1,557 measurements of the energy flux density of electromagnetic radiation (EFD) of the radio frequency range were carried out using the PZ-34 electromagnetometer with the AP3-34 SHF antenna-converter of isotropic directivity, as well as associated antennas AP3-34E USW and AP3-34N USW operating on a wireless principle ("bluetooth") and designed in a complex for measurements of the electromagnetic flux density, the mean square values of vorticity of the electric and magnetic fields in the mode of continuous generation (Figure 1). The use of these measurement means allowed to conduct the research in the most significant control points: habitable territories of populated areas, roofs, balconies, and higher floors of residential, public administration, and industrial buildings in accordance with MCI 4.3.1167-02 "Determination of the energy flux density of the electromagnetic field in the locations of radio facilities operating in the frequency range of $300 \mathrm{MHz}-300 \mathrm{GHz}^{\prime \prime}$ [1], as well as MCI 4.3.1677-03 "Determination of levels of the electromagnetic field created by radiating technical means of television, $\mathrm{FM}$ radio broadcasting and base stations of land mobile radio communication in the range of $27-2400 \mathrm{MHz}$ in their locations" [2]. To clarify the azimuth of directivity of the electromagnetic radiation from generating antennas and to search for coordinates of control points, GPS navigator GARMIN GPSMAP 64 was used in addition to the method (Figure 2), which allowed to record the sequence and location of control points for the measurement of energy flux density, to navigate the selected EMR study route, to determine the height and coordinates of control points. The Leica DISTO - D110 laser range finder was used to determine the distance from the radio transmission object. 


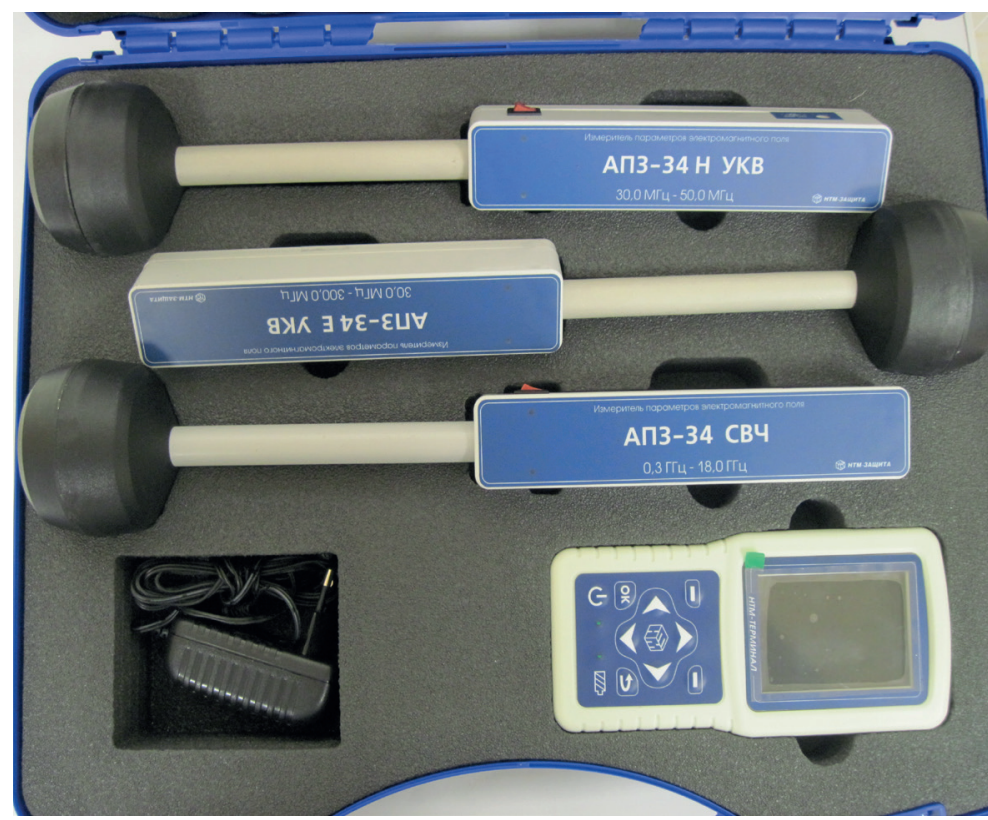

Figure 1. The PZ-34 electromagnetometer operating on a wireless principle, with 3 antenna-converters.

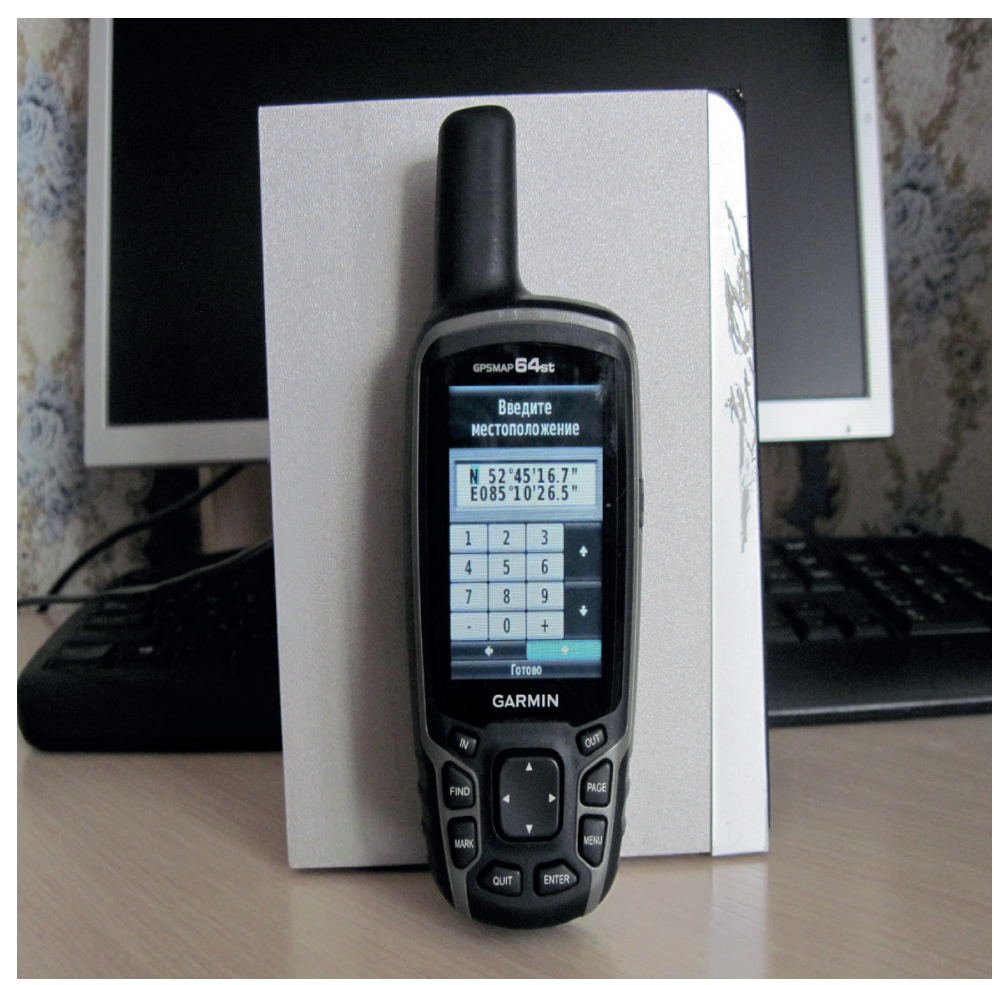

Figure 2. GPS navigator GARMIN GPSMAP 64 as an ancillary device for measuring electromagnetic radiation from TREO.

\section{Results and discussion}

One of the most important areas of the laboratory work is the radiation control of scrap metal vehicles leaving the Altai Krai and going to the largest ironand-steel works of the Russian Federation. During the stated period of time, in accordance with the guidelines of the Federal Service for Supervision of Consumer Rights Protection "Scrap metal radiation monitoring" [3], 379 scrap metal vehicles were examined (railway cars, containers, cars) with a total number of gamma radiation dose equivalent power measurements amounting to 22740 in the cities of Barnaul and Novoaltaysk, as well as at the Ust-Talmenskaya station and the Pospelikha station. In carrying out measurements of indicators of radiation safety of examined vehicles, we used a complex of dosimeter-radiometer DRBP03 with blocks BDG-01 and BDBA-02 for the study of gamma, beta and alpha radiation using an extension stem with scintillation detector, as well as with additional visual and audio-diagnostics of possible radioactive sources (Figure 3).

In addition, to achieve the necessary accuracy of measurements and to carry out in-laboratory control, a high-precision gamma radiation dosimeter DKS-AT1123 working in search and pulse mode was used, as well as the dosimeter-radiometer DKS-96 with the detection block BDMN96 (Figure 4).

According to the results of studies of indicators of radiation control of vehicles, no radiation anomalies and excess hygienic standards were revealed. During measurements, background values of the equivalent dose rate (EDR) of gamma radiation on the ground fluctuated within the range of $0.11-0.14 \mu \mathrm{Sv} / \mathrm{h}$, which corresponded to the long-term data of radiation condition monitoring in the Altai Krai during 2008-2018. With that, the values of EDR gamma radiation of the external surface of loaded vehicles were 0.12-0.18 $\mu \mathrm{Sv} / \mathrm{h}$, which did not exceed the hygienic standard $(0.2 \mu \mathrm{Sv} / \mathrm{h}$ over background) in accordance with SanPiN 2.6.1.993-00 "Hygienic requirements to ensure radiation safety in the preparation and sale of scrap metal" [4].

One of the main research directions of the Institute of Occupational Health and Industrial Ecology at present is the ecological and hygienic assessment of physical environmental factors (in particular, noise) in the allocation of land for the construction of residential, public and industrial buildings. In total, 288 measurements of equivalent and maximum noise levels were conducted for this direction in accordance with GOST 233372014 "Noise. Methods of noise measuring in the habitable territory and in the premises of residential and public buildings" [5]. Measurements were carried out both in the day (from 7-00 to 23-00) and in the night (from 23-00 to 7-00) in the cities of Barnaul and Novoaltaysk in the territories adjacent to the railway station and the airport. For noise measurements, the integration phonometeranalyzer of the 1 class spectrum Ecophysika- 
110A was used, designed for measurements of mean square, equivalent and peak sound levels, as well as for recording sound pressure levels in octave frequency bands. In order to adapt the device to the real conditions of the measurement environment and to comply with the methodology, a special tripod was applied, allowing to fix the device at a height of $1.2 \pm 0.1$ $\mathrm{m}$ above the surface level of the measuring area of the land plot, as well as a special windproof device for the phonometer microphone due to the observed wind speed of 1.2 to $4.5 \mathrm{~m} / \mathrm{s}$ (Figure 5).

In analyzing the results of measurements of noise levels, it should be noted that during the day, equivalent sound pressure levels ranged from $40.5 \pm 0.7 \mathrm{dBA}$ to $45.7 \pm 0.9 \mathrm{dBA}$ for railway noise and from $40.6 \pm 0.8 \mathrm{dBA}$ to $43.9 \pm 0.7 \mathrm{dBA}$ for air transport noise, which met hygienic standards. At the same time, during the night, equivalent noise levels exceeded the hygienic standard by 3.5-9.3 dBA for the railway transport and by 3.8-9.4 dBA for the air transport, which allowed to offer customers a complex of noise protection measures related both to the installation of noise barriers and further development of geoinformational systems of the modern city vibroacoustic emission.

\section{Conclusion}

Application of certified methods of measurement of physical environmental factors in modern conditions of compliance with the laboratory test quality management system often requires non-standard approaches, which allow, on the one hand, to adapt the measurement means to the environment objects surveyed as much as possible, and on the other hand, to ensure accuracy, traceability, objectivity, and reliability of scientific laboratory tests. The correctness of the chosen approach is confirmed by a successful round of interlaboratory comparative tests (ICT) of physical environmental factors, which the Laboratory of Labour Conditions Hygienic Monitoring passed from 18.10.2018 to 25.02.2019 with the participation of the accredited ICT provider - Ural Research Institute of Metrology.

Conflict of interest. The authors declare that there is no conflict of interest.

\section{References:}

1. MCI 4.3.1167-02 "Determination of the energy flux density of the electromagnetic field in the locations of radio facilities operating in the frequency range of $300 \mathrm{MHz}-300 \mathrm{GHz}$ ".

2. MCI 4.3.1677-03 "Determination of levels of the electromagnetic field created by radiating technical means of television, FM

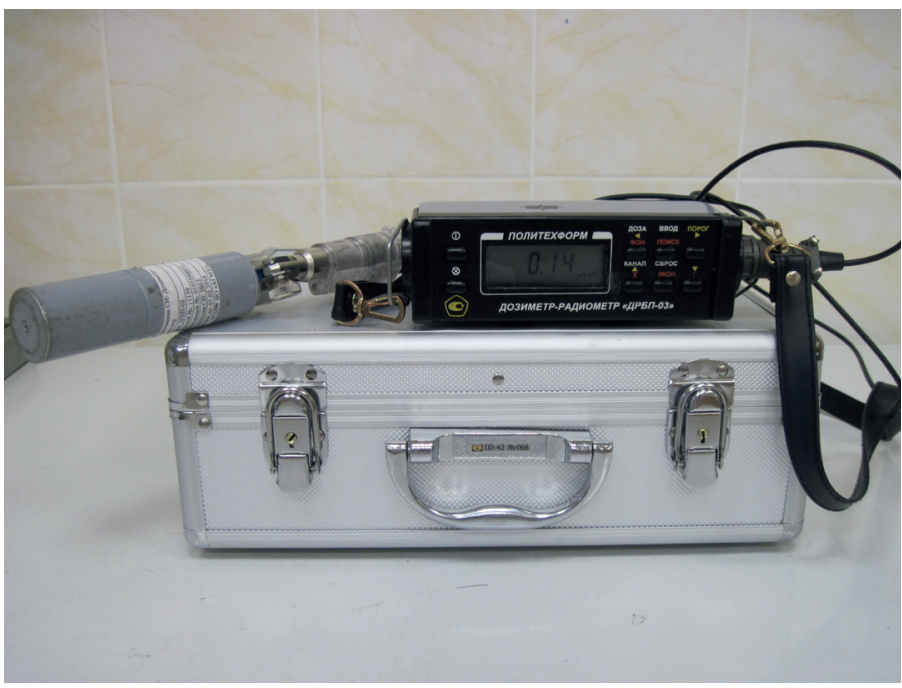

Figure 3. The dosimeter-radiometer DRBP-03 with blocks BDG-01 and BDBA-02.

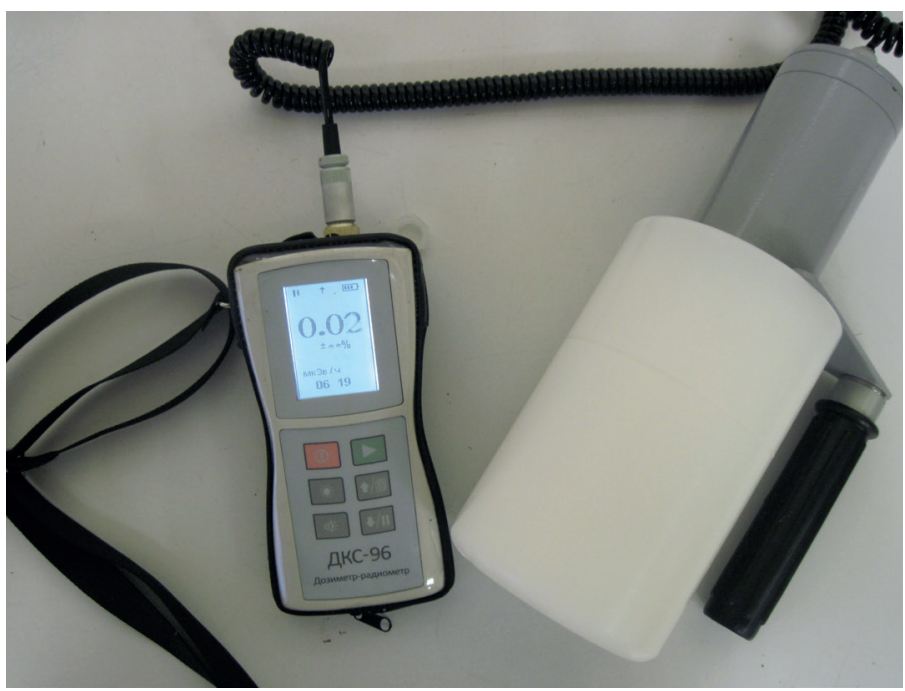

Figure 4. The dosimeter-radiometer DKS-96 with the neutron radiation detection block BDMN-96.

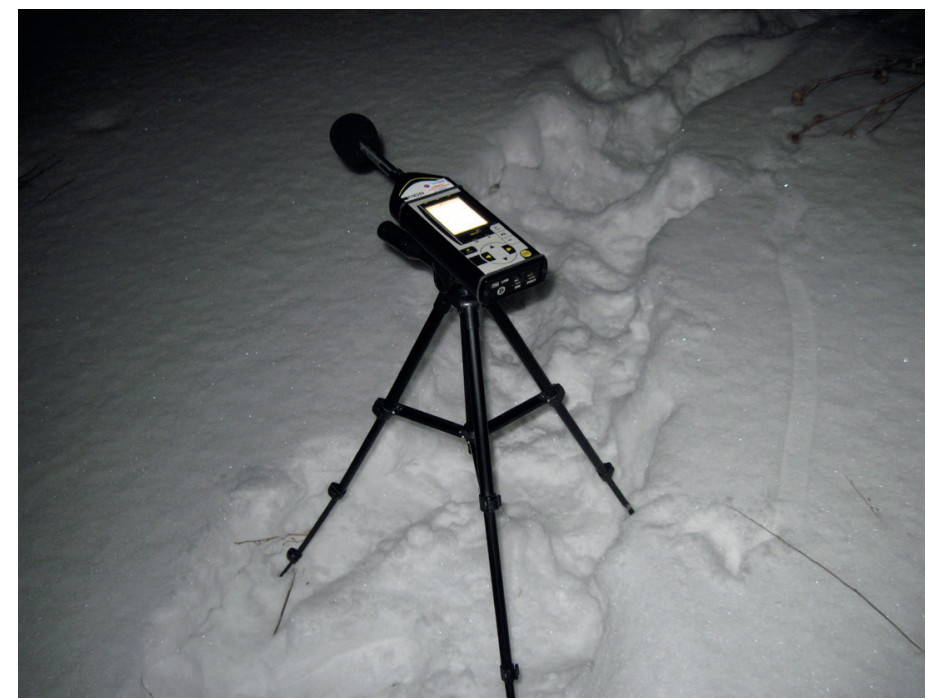

Figure 5. Location of the Ecophysika-110A spectrum phonometeranalyzer when measuring in the habitable territory during the night period. 
radio broadcasting and base stations of land mobile radio communication in the range of $27-2400 \mathrm{MHz}$ in their locations".

3. MCI 2.6.1.1087-02 "Scrap metal radiation monitoring".

4. SanPiN 2.6.1.993-00 "Hygienic requirements to ensure radiation safety in the preparation and sale of scrap metal".

5. GOST 23337-2014 "Noise. Methods of noise measuring in the habitable territory and in the premises of residential and public buildings".

\section{Contacts}

Corresponding author: Balandovich Boris Anatolievich, Doctor of Medical Sciences, Associate Professor, Head of the Institute of Occupational Health and Industrial Ecology, Altai State Medical University, Barnaul.

656038, Barnaul, Lenina Prospekt, 40.

Tel.: (3852) 566898.

E-mail: dr.balandovich@mail.ru

\section{Author information}

Tulin Nikolai Yurievich, junior research associate of the Institute of Occupational Health and Indus- trial Ecology, Altai State Medical University, Barnaul.

656038, Barnaul, Lenina Prospekt, 40.

Tel.: (3852) 566898.

E-mail: none184@yandex.ru

Kurochkina Anna Vladimirovna, laboratory assistant of the Laboratory of Labour Conditions Hygienic Monitoring of the Institute of Occupational Health and Industrial Ecology, Altai State Medical University, Barnaul.

656038, Barnaul, Lenina Prospekt, 40.

Tel.: (3852) 566898.

E-mail: anna-s-k@yandex.ru

Pasechenko Alena Olegovna, laboratory assistant of the Laboratory of Industrial Ecology, Population Health Risk Hygienic Assessment and Occupational Medicine of the Institute of Occupational Health and Industrial Ecology, Altai State Medical University, Barnaul.

656038, Barnaul, Lenina Prospekt, 40.

Tel.: (3852) 566898.

E-mail: alenapas.95@mail.ru 